\title{
Phase Transitions: In the Brain, Socio-dramatic Play and Meaningful Early Learning
}

\author{
DORIS PRONIN FROMBERG \\ Hofstra University (USA)
}

\begin{abstract}
There are similar, non-linear complex dynamical systems that underlie the epigenetic development of young children. This paper discusses the confluence of research on brain functions; a body or research that informs the characteristics of young children's play and imagination; and the ways in which young children acquire fresh perceptions and cognitions. Focus on the spaces among components of physical and interpersonal relationships can illuminate the processes of these non-linear, complex, dynamical systems. Particular implications are relevant for educational practices.
\end{abstract}

How do children before nine years of age actually learn about significant conceptual meanings, solve problems, and develop self-regulation? Educators who care to address this question--and are not content with rote memorization and children who parrot concrete verbalisms--can find some support in considering the dynamic, non-linear processes by which young children learn. Therefore, it makes sense to apprehend how young children learn in order to choreograph and coordinate how to teach in harmonious ways that do no harm.

A complex dynamical systems theory perspective can help to better understand the generative process of early childhood play and learning in human development. It is relevant to envision the non-linearity of sensitive dependence on initial conditions; the equivalence of different surface manifestations with underlying processes; dynamic phase transitions that become a template for young children's play and learning processes (See Table 1); and their interface with a content-rich, meaning-based Dynamic-Themes system of curricular implementation. Throughout the strands of play dynamics, cognitive dynamics, and curricular 
dynamics, there appear to be similar non-linear dynamical systems functioning within children's brains.

These forms share transformational relationships in which finite patterns can generate infinite possibilities. In these examples, the deep forms are predictable, and the surface forms are unpredictable. It is within the transformation (phase transition) between the deep and surface forms that meaning occurs. Phase transitions, in particular, are the spaces--a metaphorical bridge-- within relationships that function as attractors. A focus on the spaces among components of physical and interpersonal relationships can illuminate the processes of non-linear, complex, dynamic systems.

Table 1. Sample Relationships between Underlying Forms and Surface Variety

\section{Underlying Forms}

An underlying set of grammatical rules

Children use an underlying set of rules

\section{Surface Variety}

Change into different meanings as words proceed in different orders

To represent a variety of emergent meanings during play (grammar of play/script theory)

Take unpredictable forms within physical or social environments (analogical grammar of

human experience, Fromberg, 2012)
An underlying set of images in the physical world (dynamic themes, cyclical change, synergy, conflicts

By way of parallel examples, there is discussion of (a) phase transitions, along with the confluence of research on brain functions (Sprenger, 2008); (b) a body of research that informs the characteristics of young children's socio-dramatic play and imagination (Fromberg \& Bergen, 2015); and (c) Dynamic-Themes, the ways in which young children acquire fresh perceptions and cognitions (Fromberg, 2012).

\section{(A) Phase Transitions.}

A phase transition is a transition/change from one to another state in a system. Examples could include an active change or shift of focus that takes place at the fulcrum of a seesaw; learning anything new (e.g., a perceptual image, idea, physical or social skill, or emotional insight); or changing the direction of a social interaction or theme. In education, a phase transition marks the space and shift between not knowing and knowing.

The Confluence of Research on Brain Functions.

In studies of the human brain, the synapses reflect the spaces between neurons. The synapses are the phase transitions between neurons that conduct electrical and chemical impulses across various parts of the brain. There is an underlying system of relationships - as in a metaphorical use of the term, grammar-that influence the meaningful experiences within and across the 
components of the brain. Contextual relationships, as in the word orders within a language grammar, affect meaning and experience.

\section{(b) Socio-dramatic Play Grammar/Script Theory.}

Within young children's socio-dramatic play, phase transitions become observable in the predictably unpredictable trajectories of their thematic developments. For example, there are different ways in which different children at different times might negotiate entry into the imaginative socio-dramatic play framework (sensitive dependence on initial conditions), as follows:

CHILD 1: Can I play doctor with you? [This might occasion a yes or no response.]

CHILD 2: Here's another bandage. [This offer of a play prop might help to gain entry into an existing play script - or not.]

CHILD 3: My baby broke his arm. Can you fix it? [This offer of a continuation of the play script might help to gain entry - or not.]

CHILD 4: My husband fell down drunk. Let's carry him over there. [This offer of an embellishment of the play script might help to gain entry - or not.]

CHILD 5: There's a monster at the door and we need to run and hide. [This might disrupt the medical play for some or all of the players.]

Each child's past event knowledge reflects a different system of components which influence a distinctive phase transition into a different response by Children 2-5 to Child 1 . Observing the strategies of each child provides a window through which to assess the social skill and prior event knowledge/experience of the child.

\section{(c) Dynamic-Themes: An Analogical Grammar of Early Human Experience}

The Dynamic-Theme is an underlying image that children can perceive in a variety of surface forms. Professional teachers know how to integrate, within engaging experiences, an underlying Dynamic-Theme that cuts across disciplines. The isomorphic imagery created by the comparison (phase transition-space) between the underlying Dynamic-Theme that is represented in different surface forms facilitates new perceptions and ideas. Teachers provide a variety of active social, scientific-physical, and artistic experiences that share a repeated underlying Dynamic-Theme, such as cyclical change or dialectical contrasts-conflicts. The underlying Dynamic-Theme makes it easier to perceive new ideas within different surface forms. The term, dynamic, indicates movement. Connections and movement are consistent with how our brains function (Tognoli \& Kelso, 2008; Sprenger, 2008). Dynamic-Themes are similar images that serve as conceptual organizers. The use of Dynamic-Themes for educational planning can help to integrate learning across subject matter.

Neuroscientists contend that the neural networks of the brain support these flexible and transformational processes (Payne \& Kounios, 2008; Tognoli \& Kelso, 2008). They tell us that local neural circuits radiate collectively and globally within the brain (Kohonen, 1989). It would 
follow that it is easier for children to integrate perceptions and meaning when you carefully sequence and pace activities that share an underlying pattern.

Iso(same)morphism(shape) is a shorthand way to refer to these underlying relationships that may take different surface forms; analogies help humans infer the isomorphic connections. Analogies, built from cognitive connections based upon personal experiences, help children absorb the connections (Fromberg, 2015). Young children are intuitive thinkers who are at their zenith of flexibility for thinking and ordering the world; they directly and intuitively experience isomorphic relationships because their analogical thinking and isomorphic imagery is so powerful and fluid. They readily "blend" images that are "evident in such experiences as pretense, fantasy, humor, expectation, prediction, analogy, and problem solving (Fauconnier \& Turner, 2002, p.57)." For example, at the moment of problem solving, the connection process is integrative, not a structure of steps.

\section{An Analogical Grammar of Early Human Experience}

Dynamic-Themes are the analogical/isomorphic images that underlie the meanings that children create as they engage in direct experiences. The Dynamic-Theme is an underlying image that children can perceive in a variety of surface forms; a particular Dynamic-Theme (isomorphic image) can appear transformed in a variety of direct experiences. Youngsters implicitly experience the Dynamic-Theme as a connection-making process, an analogical 'grammar of experience.' Dynamic-Themes offer a way to connect young children's grammar of experience with the teacher's capacity to create phase transitions between not-knowing and knowing.

For example, children might experience the Dynamic-Theme of cyclical change directly within animal, plant, or human growth; as well as weather; or chemical changes. The DynamicTheme of synergy underlies cooking/chemical processes; explosive/self-organizing physical events; milling group behavior becoming a mob; cooperative constructions; square dancing; and plant or animal gestation. Children might experience the Dynamic-Theme of dialectical activity (contrasts-conflicts) in such direct experiences as scarcity; aerodynamics; voting; and interpersonal conflict. So, Dynamic-Themes cut across emotional, social, aesthetic, and physical experiences as well as subject matter disciplines.

This curricular approach is not a magical pill for uniform application. However, it offers a way in which each teacher and group of children may negotiate and construct together their own 'fingerprint of experience.' These fingerprints may differ on the surface from group to group but still share similar underlying meanings.

Meaning is lymphatic. Reality is complex and non-linear, and meaning is the dynamic relationship between experiences. Dynamic-Themes reflect this complex and non-linear nature of reality.

Teachers and Children Construct Dynamic-Themes through Phase Transitions

Pre-kindergarten and kindergarten children access Dynamic-Themes by using their imaginations and by making connections with familiar concepts, in effect, using analogous thinking. Professional teachers have considered which activities offer children many opportunities for making connections, perceiving relationships, and they have integrated conditions for learning that create opportunities for phase transitions. Among the seven integrated conditions that support early learning through dynamic relationships, are the following: 
(1) Inductive learning with contrasts and comparisons. Professional teachers know how to control variables so that children might more readily perceive fresh perspectives, ideas, or skills. For example, young children typically find inductive learning (comparing relationships) more accessible than deductive learning (applying a generalization). In learning about concepts of color or size or shape, any concept is more accessible if the other variables are the same. To identify color, the size and shape of other items would remain the same. To identify shape, the color and size of other items would remain the same.

2) Cognitive dissonance consists of an expectation-experience-surprise experience. For example, young children might expect a larger horseshoe magnet to be stronger than a smaller bar magnet until they add one paper clip at a time to each magnet and experience the surprise of the smaller magnet's superior strength.

(3) Social interaction can support social competence. The feedback that children receive within social interactions demonstrates and teaches them alternative ways to interact in future. They learn to de-center from themselves and what they might expect about others' motives, beliefs and thoughts, thereby increasing their potential for self-regulation.

(4) Physical interactions provide imagery that offers active comparisons and contrasts that utilize the plasticity of young brains. For example, using different three-dimensional materials and strategies, children receive information concerning quantitative concepts as well as balance and gravitational limitations.

(5) Play, particularly socio-dramatic play with others, affords opportunities to "scaffold (support and build) each other's participation and learn from seeing the experiences other children dramatize... a form of collaborative oral playwriting (Fromberg, 2012, p.49)."

(6) Revisiting emotional, social, and physical situations offers opportunities to compare and contrast experiences as well as make fresh connections to intervening events.

(7) A sense of competence builds on a preponderance of successes that cushion setbacks in order to build and support resilience and self-regulation.

Professional teachers know that children are likely to devote their attention to ideas that have significance in their lives. They recognize that emotional experiences often underlie and define the degree of significance of ideas. When you plan activities with a Dynamic-Theme in mind, the focus is on relationships and opportunities for children to perceive connections. Perception takes place more easily when there is movement between images. Children directly experience the images within each Dynamic-Theme as they participate directly in activities. The underlying images (perceptual models) help children to make connections with new experiences and ease the transfer of learning to solving new problems.

\section{Concluding Comment}

Phase transitions focus on the relationships/the spaces between, components or phenomena. Phase transitions are present in the brain's synapses; social interactions within socio-dramatic play oral scripts; and the comparisons within components of early skills and concept learning. Phase transitions also reflect the isomorphic nature/relationships of underlying Dynamic-Themes that represent physical-scientific, social, literary, and artistic surface forms. Professional teachers and other adults who recognize the dynamic nature of phase transitions are able to embrace the predictable unpredictability of learning, the power of active engagements by learners, and those things that make being human most significant. 


\section{References}

Fauconnier, G., \& Turner M. (2002). The way we think: Conceptual blending and the mind's hidden complexities. New York: Basic Books.

Fromberg, D.P. (2012). The all-day kindergarten and pre-k curriculum: A Dynamic-Themes approach. New York: Routledge.

Fromberg, D.P., \& Bergen, D. (Eds.). (2015) Play from birth to twelve: Contexts, perspectives, and meanings. New York: Routledge.

Fromberg, D.P. (2015). How nonlinear systems inform meaning and early education (pp. 419-434). In D.P. Fromberg \& D. Bergen (Eds.), Play from birth to twelve: Contexts, perspectives, and meanings. New York: Routledge.

Kohonen, F. (1998). Self-organization and associative memory 3rd ed. New York: Springer-Verlag.

Payne, L., \& Kounios J. (2009). Coherent oscillatory networks support short-term memory retention. Brain Research, 1247, 126-132.

Sprenger, M. (2008). The developing brain: Birth to age eight. Thousand Oaks, CA: Crown.

Tognoli, E., \& Kelso, J.A.S. (2008). Brain coordination dynamics: True and false faces of phase synchrony and metastability. Progress in Neurobiology, 87, 31-40.

\section{About the Author}

Doris Pronin Fromberg is Professor Emerita and has served as chairperson of the Department of Curriculum and Teaching, Hofstra University. She is past-president of the National Association of Early Childhood Teacher Educators (NAECTE); chaired the Special Interest Group on Early Education and Child Development of the American Educational Research Association; and the Special Study Group on Elementary Education of the American Association of Colleges of Education. She is an advocate for high quality early childhood education, early childhood teacher education, and early childhood administrator education; and consideration for the dynamic nature of learning and education. Correspondence: Doris.P.Fromberg@hofstra.edu

(C) Copyright 2017. The author, DORIS PRONIN FROMBERG, assigns to the University of Alberta and other educational and non-profit institutions a non-exclusive license to use this document for personal use and in courses of instruction provided that the article is used in full and this copyright statement is reproduced. The authors also grant a non-exclusive license to the University of Alberta to publish this document in full on the World Wide Web, and for the document to be published on mirrors on the World Wide Web. Any other usage is prohibited without the express permission of the authors. 